Article

\title{
Environmental Worldviews: A Point of Common Contact, or Barrier?
}

\author{
Caroline L. Noblet $^{1, *}$, Laura A. Lindenfeld ${ }^{2}$ and Mark W. Anderson ${ }^{1}$ \\ 1 School of Economics, University of Maine, Orono, ME 04469, USA; \\ E-Mail: mark.anderson@umit.maine.edu \\ 2 Department of Communication and Journalism, University of Maine, Orono, ME 04469, USA; \\ E-Mail: laura_lindenfeld@umit.maine.edu
}

* Author to whom correspondence should be addressed; E-Mail: caroline.noblet@maine.edu; Tel.: +1-207-581-3172; Fax: +1-207-581-4278.

Received: 19 September 2013; in revised form: 1 November 2013 / Accepted: 4 November 2013 / Published: 11 November 2013

\begin{abstract}
Increasingly, scientists are reaching out to individuals and entities once considered "users" of scientific knowledge to engage them in the research process due to the increased need for contextualized knowledge. However, these increased interactions make apparent the boundaries that exist between the parties interested in sustainability science. Divergent values and attitudes amongst researchers and between researchers and stakeholders may preclude effective communication and collaboration when individuals screen information due to their perceptions of those who generated the information. The current work contributes to the complexity of environmental communication in the decision making sphere, by considering whether expressions of personal value, such as environmental worldviews, may influence the processing of knowledge and information sharing across interdisciplinary research and researcher-stakeholder boundaries. This work includes a unique opportunity to consider not only empirical data, but interactions and implications within a research community and with the public.
\end{abstract}

Keywords: environmental worldviews; boundary management; stakeholder engagement; sustainability science; co-orientation model 


\section{Introduction}

A significant part of the sustainability research agenda is to better understand the effectiveness of linking knowledge with action in sustainability science, particularly with respect to differences across academic disciplines and the stakeholders with whom scientists wish to engage [1,2]. Given that sustainability is ultimately about the ability of our own and future generations to meet their own needs [3], it becomes increasingly important to understand citizen needs and barriers to sustainable choices. Kates [4] (p. 33) indicates that "Knowledge for sustainability should be salient for user needs and problems, credible both to other scientists, practitioners, as well as users, and seen as legitimate by all in the process that produced it". The movement of knowledge into action is a complex system that deserves additional examination into the barriers that may impede success, and, in turn, the factors that may promote it.

Traditionally a one-way flow of information has existed from researchers to decision-makers to citizens, with no channel returning back for a two way flow [5]. These traditional models for science transmission promote the perception that "the science community is... an arena separate from those that might use the products of research" [1]. These models, based upon the trickle-down assumption, imply that researchers are not responsible for the uses of their knowledge and thus researchers are truly not involved in the policy-decision phase. The so called "top down" or "loading dock" model relied on scientists to provide knowledge as they saw fit assuming that decision-makers would appropriately interpret and use the information for improving policy [6]. These models involved explicit roles for the government, industry and higher education where each entity was compartmentalized following own social norms [7]. Indeed, classic literature on the politicization of science encouraged separation of these groups to lessen the erosion of objectivism in science [8]. An evolving new contract between these entities has begun to erase the borders between separate silos and disrupt the Linear Model of Science: a model used to describe the flow of scientific information from basic research to applied research to society [7].

Decision makers and citizens alike are no longer satisfied with processes involving scientific information which fail to allow society to participate [7] There is growing participation by the public not only in contributing to science generation (science for policy) but also in setting scientific agendas and priorities (policy for science) [9] The media has played an increasingly active role in this new dialogue between science and society by helping society "speak back" to those engaged in scientific research [7] This incorporation of a dual flow of information (from science to society and society back to science) has led to an increased desire for contextualized scientific knowledge. Pursuing such contextualized knowledge solutions for sustainability science provides increased opportunities for interactions between scientists, decision-makers and citizens. It becomes imperative that these interactions are productive and that careful consideration is given to potential common ground upon which these interactions may be built or alternatively, boundaries which may exist.

\subsection{Boundary Perspectives}

Given the above call for contextualized knowledge, increasingly scientists are reaching out to individuals and entities once considered "users" of scientific knowledge to engage them in the research 
process. However, increased interactions make apparent the boundaries that exist between the parties interested in sustainability science. Boundaries are often considered to be an acknowledgement that different interests (i.e., different groups) may have different objectives, knowledge and desired outcomes regarding scientific information [10]. Often these boundaries are political in nature where these differing interests may actually impede information and knowledge sharing despite interests in a common challenge. A slightly different but related perspective, generally consistent with the views of Cash and colleagues [6,11], interprets boundaries as an opportunity to recognize and emphasize commonality between different groups, including the ability to share knowledge. The current work extends these considerations to investigate whether expressions of personal value, such as environmental worldviews, may be a source of difference or commonality between individuals and groups engaged in sustainability science.

Boundaries may vary in complexity and exist between a myriad of groups [10]. Cash and colleagues [11] note that boundaries may exist between scientists and policy makers; between academic disciplines; and between public and private sectors. Additionally, Cash and colleagues note the prevalence of boundaries between academic disciplines [11]. Further management of boundaries between science and policy has long been recognized as crucial in decision making [8]. We also note a crucial additional boundary challenge between engaged stakeholders (i.e., policy makers or involved citizens), researchers and the unengaged stakeholder (i.e., the general public). For ease of discussion, we use the term "general public" or "unengaged stakeholder". However, we recognize that there is tremendous variation within this group with additional inherent boundaries that are not directly addressed within this article. The existence of these boundaries has important ramifications for the ability of researchers, engaged stakeholders and unengaged stakeholders to tackle sustainability. For example, traditionally scientists have relied on engaged stakeholders to translate scientific information for unengaged stakeholders. This translation may not be seamless given the existence of boundaries between these groups, a concept further investigated by this study.

The current work recognizes the potential for personal values to influence the process of knowledge and information sharing across these boundaries. This investigation is consistent with previous work which initiates the study of differences in pre-cursors to attitudes (including values and beliefs) across populations [11] As noted by Cox [12] (p. 33) the "link between scientific research and public policy is not always direct", as researchers and community collaborators serve as the mediators between sustainability science and public engagement; where, in the words of Lakoff [13] (p. 80) "the messenger matters". Thus a lack of consistency or agreement within the research community may degrade the perceived trustworthy nature of researchers, those who collaborate with them and their scientific message and products. Divergent values and attitudes amongst researchers and between researchers and stakeholders may preclude effective communication and collaboration when citizens screen, dismiss, or question scientific information due to their perceptions of those who generated the information.

Even more complicated is the act of moving knowledge into action across the general population or unengaged stakeholders. As Hart and Calhoun [14] (p. 260) argue, "Many decisions are affected by values, attitudes and belief systems that are completely unrelated to or in direct conflict with rationales based on scientific information". Thus, the success or failure of transferring sustainability science research-based knowledge into environmental or political action is affected by underlying values of the researchers and stakeholders, which may include not only environmental policy makers but also the 
entire population served by them. As indicated by Lindenfeld et al. [15] (p. 16) "communication processes must attend to social values to build trust and collaborative partnerships".

The success of communication and collaboration between parties, particularly ones as potentially diverse as university researchers and stakeholders, can be influenced by the accuracy of assumptions across the two parties [16]. The co-orientation model is a frame used to understand and measure differences across viewpoints in related parties, where measurement of each group's own view of an issue is equally as important as estimation of the other group's view. Here we seek to study the agreement, congruency, and accuracy between sustainability researchers and stakeholders in a modified co-orientation framework.

\subsection{Environmental Ideology}

The persuasiveness of a message regarding environmental decisions can be influenced by both individual and group considerations [12], and that these messages may be viewed quite differently by different members of the public depending upon their prevailing worldview [17,18]. A worldview is an individual's belief about one's own role in the world. The New Ecological Paradigm (NEP), a measure of general pro-environmental and ecological worldview, has been used as the primary metric in many studies to capture an individual's existing environmental proclivities [19-25]. The NEP has been used in measuring the: values of whole populations [26], the impacts of education on attitudinal change [27], as a mediator in predicting environmental behavior [28], attitudes towards persuasion agents [25] and, in its earlier version the New Environmental Paradigm, other aspects of environmental worldviews [29,30]. We acknowledge that the NEP as a metric has shortcomings, many of which are noted in recent work by the authors [31]. This study uses NEP as a measure of environmental ideology, a lens through which we interpret information about our world [17]. We seek to extend the current literature by using the NEP as a means of better understanding research partners and whether they interpret the world in similar or different ways. Thus we have the unique opportunity to consider not only the data collected during research projects, but how we interact as a research community and with the public.

The current study will contribute to this important discourse regarding the complexity of communication in the decision making sphere by addressing differences in worldviews (as measured by the NEP) across and within three unique populations: faculty researchers involved in a large, multiyear, interdisciplinary research project at the University of Maine, the Sustainability Solutions Initiative (SSI); engaged stakeholders associated with SSI related research projects; and the general Maine public (unengaged stakeholders). This work has implications for knowledge-sharing behavior in the public sphere by examining the intersection of communication with existing worldviews and persuasion theories in environmental decision making. In addition, the interdisciplinary scope of this work will add a unique perspective to the environmental communication discourse.

\subsection{Worldview Differences within the Research Population}

Sustainability science draws academic researchers from widely varied disciplines. Naturally such highly interdisciplinary teams will face unique boundaries and partnership challenges as they address the myriad of issues associated with sustainability. Researchers focused on this area may all agree that sustainability research is a distinct priority; however, they may find themselves at odds with one 
another over the priorities within the field. Sustainability and boundary literature has noted that researchers have pre-existing worldviews themselves [32,33], and that perceived or actual differences in these views may have significant impact on their ability to collaborate; Guston [34] (p. 399) notes that "science is not devoid of values prior to politicization".

Given the preponderance of studies that use the NEP as a measure of endorsement of pro-ecological worldviews (recent examples [19,20,22-26,28,35-37]), and the current interest in the literature regarding the NEP's ability to differentiate within populations, the opportunity to investigate any difference in NEP scores across a population of sustainability scientists presents an interesting challenge. The first subset in question-faculty in the SSI-are researchers actively engaged in knowledge co-production and collaboration with stakeholders, a strategy designed to improve the usefulness of science and align the supply of and demand for science. Furthermore, an SSI objective is to link knowledge with action in the policy arena and respond to community research needs, where differing worldviews may hinder the complex process of developing and communicating knowledge and needs among diverse groups of researchers and stakeholders. The complexity of sustainability science requires both interdisciplinary (reaching across disciplines) and transdisciplinary (reaching beyond academic institutions) work [15]. Thus differing worldviews within the SSI faculty may hinder the ability of the researchers to collaborate on interdisciplinary research and complicate the ability of university representatives to work with groups outside the university's walls. This, in turn, can hamper science communication processes with Maine policy makers and communities. As noted by Norton [32] even among those who self-identify as "environmentalists" there is not a single worldview. Norton [2] also considered how differences in academic disciplines relate to the concept of sustainability, providing an excellent foundation for this preliminary research.

Cognizant of the potential differences between researchers from diverse disciplines, the SSI includes a core research focus on the project's interdisciplinary collaboration. SSI's Organizational Innovation (OI) research investigates the team's ability to work across various ontological and epistemological frameworks. The current study falls in this OI paradigm and was designed both to produce meaningful research outcomes for publication and to feed back iteratively to the team to support its ability to work collaboratively within and across the university's walls. Previous findings by SSI's OI team indicate that a significant difference exists between social scientists' and natural scientists' researchers on the SSI team with respect to stress levels and feelings of ownership for linking Knowledge with Action and Environmental Solutions [38]. Consistent with McCoy and Gardner [38], this study hypothesizes that significant differences between natural and social scientists will exist within worldviews, where natural scientists will tend to have higher NEP scores given the additional stress they felt for creating environmental solutions. Second, the environmental literature (e.g., $[37,39,40]$ ) has noted that gender is often a significant determinant of environmental proclivities. While this finding may hold true in the general population, others find that, among scientists and managers, gender is less important in environmental proclivities [35]. Differences in faculty NEP scores across gender will be tested: given that all of the men and women in this sample have dedicated their careers to environmental issues, consistent with Steel et al. [35], the hypothesis for this aspect is that no difference will exist across gender on the NEP. 


\subsection{Disconnect between Researchers and Stakeholders}

The evidence from the literature is clear: Differences in values, worldviews and culture can influence how one perceives and interprets messages $[25,41,42]$. While the complexity of sustainability communication cannot be captured with one construct, the self-construal role of worldviews in this process deserves further exploration, particularly as we seek empirically to understand existing differences across populations. Importantly, "human's relationship with the environment is a core dimension of cultural worldview" ([25] p. 8), and thus environmental worldviews may serve as an important component in the success of environmental communication [17]. However, existing models in communication and psychology literature offer conflicting implications for circumstances where worldviews are disparate (or similar) across populations, which we will explore here.

Sustainability scientists are increasingly serving as the direct messengers of sustainability issues. With new technologies in communication, citizens may no longer rely on traditional mass media, nor receive the filtering effect of this media with respect to sustainability issues; in part because of the recognition of the unequal coverage of environmental issues [28,43]. Increasingly citizens may obtain sustainability science information directly from a researcher's personal website or face-to-face during research project engagement. Thus a researcher's framing and lexical choices impact the perception of the messenger (researchers) and, in turn, the reception of their messages. Discursive practices of researchers are now central components of how issues are constructed, conveyed, and filtered by citizens and stakeholders alike as researchers strive to recognize that sustainability messages may encounter multiple interpretations. It becomes crucially important that efforts to engage in sustainability communication are grounded in a strong understanding of the complexities of stakeholder relationships [44]. Circumstances will arise where all parties interested in sustainability science will not be in agreement, but if we are able to understand to what extent we may be starting from common ground, and how important that common ground may be in potential interpretation due to common worldviews, we may increase chances of productive interactions.

We draw from the co-orientation model $[44,45]$ to consider the relationship between stakeholders (citizens) and actors (here, university researchers) (Figure 1). We recognize that the potential exists for worldviews between stakeholders and organizations to differ, and have implications on communication [44]. First, we recognize that the phrase "stakeholder" has come to mean many things to many people. Freeman's [46] definition of a stakeholder is "a group or individual who can have an effect on or be affected by the actions of an organization", here university researchers engaged in sustainability science may substitute for organization. Definitions may initially have been oriented with the traditional for-profit firm in mind, but we extend this to incorporate university researchers as principles and the general public as one group of stakeholders.

Importantly, we recognize that as stakeholders and university researchers engage in sustainability dialogue, any information presented amongst these entities is filtered by existing worldviews, and it is only after this filtering process that people reach conclusions and take actions [46]. This interpretation process may leave information that is inconsistent with prevailing worldviews to be "undervalued or even ignored" [44]. Given the urgency of sustainability problems, we can ill afford to lose opportunities for sustainability science research results to improve decision making and actions. Consistent with the co-orientation model, congruency of stakeholder views on an issue, coupled with 
their perception of an agent's view is one of the four key pillars of the model. The specter of false conflict looms large for parties engaged in evaluation of a situation; where the parties believe they disagree but in truth, they do not. Brønn and Brønn [44] (p. 13) indicate that false conflict occurs when "the organization and the stakeholder(s), believe that they disagree on an issue, policy or action, when in fact they agree". This model indicates that meaningful consensus on an issue can only be achieved when stakeholders and agents know that they share agreement in their evaluation of an issue. Thus for best results in sustainability science, this model indicates that researchers and stakeholders must identify and build upon common ground such as shared environmental worldviews.

Figure 1. Modified co-orientation model (adapted from [44,45].

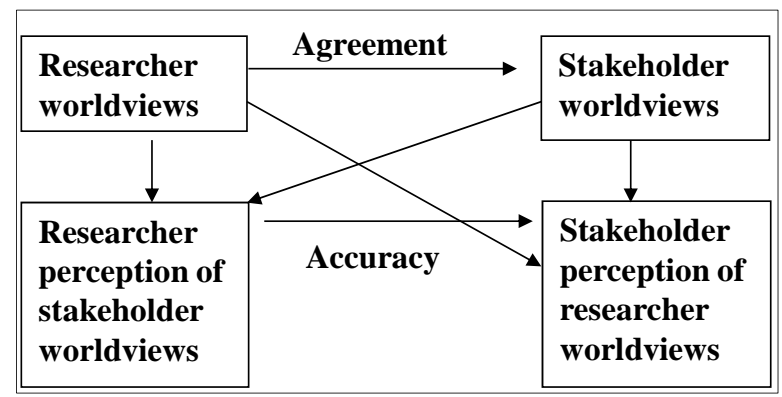

The Persuasion Knowledge Model [47] and related persuasion literature points to additional complexities inherent in these relationships. In an adaptation of this model, university researchers may be seen as "persuasive agents" in their efforts to discuss the breadth of sustainability research and the contextual implications of their own work. Previous literature indicates that a stakeholder/citizen's knowledge and trust of the persuasive agent (here, university researcher) has implications for the perceived trustworthiness of the message (particularly if the citizen lacks topic knowledge) $[25,43,48]$. In addition, Magee's work [25] (p. 13) indicates that one's worldview can exert influence on a person "without conscious awareness" and that holding similar worldviews with a persuasive agent may increase the effectiveness and reliability of the message (emphasis added). Related persuasion literature [49] notes that the credibility of a message may actually be impacted in different ways dependent upon whether the persuasive agent (here, university researcher) is similar or dissimilar to the citizen (the message receiver). For messages related to judgments and opinions, citizens are more influenced by people similar to themselves (emphasis added). However, for factual material, such as scientific fact, citizens are more influenced by knowledgeable people who are dissimilar (emphasis added).

These ostensibly conflicting models leave an unanswered question to be explored: Are citizens/stakeholders more likely to engage with researchers whom they perceive as sharing worldviews, or do they look to researchers to provide factual knowledge precisely because they perceive them as unbiased or holding different worldviews? Do researchers inadvertently choose their stakeholders based on similar worldviews, thus negating the voice of conflicting views? It is imperative that we begin to understand the worldviews of all engaged in sustainability issues, in response to the call by Brønn and Brønn [44] (p. 9, emphasis added) that "a primary task of communicators with respect to organizational stakeholders is to work actively to attempt to uncover and understand the stakeholders' mental models" (but also) "must also be prepared to continuously test and update its own mental models". 
This analysis seeks to uncover the environmental worldviews of engaged stakeholders, unengaged stakeholders (i.e., citizens) and researchers alike within a particular sustainability science research context. We then seek to empirically test differences among these samples, including potential perceptions about the congruency (or lack thereof) of worldviews and provide potential direction for future communication research.

\section{Methods}

\subsection{Sampling and Survey Administration}

This analysis utilizes data from three separate surveys with overlapping components.

\subsubsection{Faculty Survey}

The first survey is of SSI Faculty regarding their worldviews was conducted in 2010. This survey, a forty-three question instrument administered via online data collection tool, included questions encompassing the NEP, as well as views of sustainability, technology, and individual socio-academic characteristics. The participants were unaware of the aim of the survey. Fifty-eight respondents participated in the survey (93\% response rate), including 34 male and 23 female respondents. Twelve female social scientists, 10 female natural scientists, 20 male natural scientists and 13 male social scientists are represented in the sample. Respondents across all surveys were instructed to skip questions that they were uncomfortable answering, thus not all participants provided gender, discipline or responses to all questions.

\subsubsection{Population Survey}

The second component of the analysis is based upon a mail survey administered to a random sample of 3000 Maine citizens. The sample frame consisted of three distinct sub-samples: a land-based sample, a coastal sample and a general population sample. In spring of 2010 researchers documented existing and proposed land-based wind facilities and recorded all communities that directly surround or contain an existing land-based wind energy facility. The land-based sub-sample consisted of these 60 towns, where $20 \%$ of the total sample consisted of households residing in these towns. Second, researchers documented coastal towns/cities of Maine. For the coastal sub-sample, we did not want to oversample southern coastal Maine (the counties of York and Cumberland) given that this region of the state is highly populated and would already be captured in general population sampling. The coastal sub-sample consisted of 77 towns from the remaining coastal counties and would represent $20 \%$ of our total sample. The remaining $60 \%$ of the sample consisted of randomly selected Maine citizens from around the state.

Our sample was obtained from InfoUSA, a recognized leader in provision of accurate targeted mailings. The target population for the survey was any Maine citizen over the age of 18, thus this framework should provide an adequate sample. The survey was administered in a two-round modified Dillman method between April and August of 2010 [50]. Each round after the initial introduction letter (350 returned undeliverable despite Postal System address certification) presented the participant with a copy of the survey, a reminder letter, and a one-dollar cash incentive. The total number of 
respondents was 1260, with 350 undeliverable and 25 surveys returned refused, for a response rate of $48 \%$ percent [1260/(3000-350)]. The survey instrument consisted of five variations, allowing for cross-disciplinary modeling. The survey instrument was the collaborative effort of SSI faculty representing three disciplines: Economics, Communication, and Psychology. The survey instrument consisted of five to six sections, dependent upon version. Section I solicited respondents background knowledge about wind energy in Maine. In Section II respondents were asked to express their views on potential benefits and concerns of wind power. Section III contained one of three components, either a choice of different energy types (conjoint), a respondent's perceptions of where to obtain information on wind energy in Maine (trust component), or alternative message framing about wind energy potential in Maine. This analysis will utilize the trust component. Section IV collected information on a respondent's environmental and other attitudes and behaviors, including responses to the NEP question set and various attitudinal and behavioral constructs including propensity to buy American-made products, perception of "greener" products and beliefs regarding energy security. One-hundred and fifty respondents completed the full set of NEP questions, 86 males and 64 females. The final section consisted of demographic questions.

\subsubsection{Stakeholder Survey}

The third portion of the analysis is based upon a survey instrument administered to stakeholders participating in two conferences, the Maine Wind Conference (24-25 January 2011) and the Maine Water Conference (14 March 2011), both held in Maine's capital, Augusta, located in the central part of the state. This survey was a forty-eight question instrument administered via surveymonkey ${ }^{\mathcal{O}}$, which included questions encompassing the NEP and views of sustainability, technology, and individual socio-academic characteristics. One hundred and two stakeholders participated in the survey including 50 male respondents and 42 female respondents. Stakeholders were also asked to identify the discipline in which they received their highest educational degree, where $69 \%(n=59)$ of respondents identified themselves as holding degrees in natural science fields and $31 \%(n=29)$ held social science degrees.

\subsection{Data Analysis}

The NEP scale consists of 15 statements (Table 1), with which a respondent indicates agreement on a Likert scale ( 1 = Strongly Disagree; 5 = Strongly Agree). There are eight statements that assert an attitude of environmental concern, such as "We are approaching the limit of the number of people the earth can support". These are the odd numbered questions on the instrument. There are seven questions that suggest an opposite, or more anthropocentric, attitude (the even numbered questions), such as "Humans have the right to modify the natural environment to suit their needs." The creation of an NEP score variable is a composite variable vetted for reliability where deletion of any item from the scale lowers the reliability score; consistent with existing literature [51,52]. Cronbach's alpha above 0.70 indicates reliability of the scale. To perform beginning analysis on the faculty data, the set of questions used in the NEP were recoded, and variables were computed, transforming the even questions to indicate environmental concern. When checked for normality assumptions, i.e., lack of skewness and kurtosis, with respect to the variables of interest, gender, and discipline the data are found to be 
normal. However, given the small sample size it is appropriate to utilize non-parametric methods in analyzing the data. Thus the Wilcoxon Test, the non-parametric analog of t-test, was employed to determine statistical differences across NEP by gender and discipline within this sample.

Table 1. New Ecological Paradigm (NEP) component matrix.
(1) We are approaching the limit of the number of people the earth can support.
(2) Humans have the right to modify the natural environment to suit their needs.
(3) When humans interfere with nature it often produces disastrous consequences.
(4) Human ingenuity will insure that we do not make the earth unlivable.
(5) Humans are seriously abusing the environment.
(6) The earth has plenty of natural resources if we just learn how to develop them.
(7) Plants and animals have as much right as humans to exist.
(8) The balance of nature is strong enough to cope with the impacts of modern industrial nations.
(9) Despite our special abilities, humans are still subject to the laws of nature.
(10) The so called ecological crises facing humankind has been greatly exaggerated.
(11) The earth is like a spaceship with very limited room and resources.
(12) Humans were meant to rule over the rest of nature.
(13) The balance of nature is very delicate and easily upset.
(14) Humans will eventually learn enough about how nature works to be able to control it.
(15) If things continue on their present course we will soon experience a major ecological catastrophe.

Similar to the analysis employed with the faculty data, the analysis of similarity among researchers, stakeholders, and Maine's citizens began with recoding of the NEP variables and included checking the reliability of the NEP for each participant group (researchers, alpha $=0.86$; stakeholders; alpha $=0.83$ and citizens alpha $=0.85$ ). The reported Cronbach's alpha are consistent with other reliability findings for this scale [20,24,37] and indicates strong internal reliability. The mean NEP score for each representative group was computed, and statistical differences across these three groups were examined. We employ non-parametric analysis in comparing the differences within, and across the three groups for two reasons: (1) as noted above, our samples are small. Parametric analysis assumes that the distribution of the variables within a sample are normal; however small sample size limits the reliability of normality assumptions, and (2) the three samples were collected in different ways. These methods decreased the likelihood that individuals had an equal chance to be selected into our surveys (for example, the stakeholder survey was a convenience sample; and the citizen sample over weighted certain areas of the state). This methodology limits the reliability of normality assumptions which underlie parametric tests, and would be best addressed using non-parametric approaches that do not rely on this assumption. We employ Wilcoxon Tests as the non-parametric analog to t-tests, Kruskal-Wallis tests to compare differences in means across the three samples and Chi-Square analysis to examine distributional differences among our three groups of interest.

In addition, citizens in the general population survey were asked questions about their preferred source of information on wind energy in order to assess the extent to which citizens trust university researchers and examine why researchers may be trusted; these questions included the potential role of shared values. We maintain that wind energy information is an appropriate application given that the energy portfolio composition (particularly the role of renewable energy) is a pressing sustainability 
science issue. Respondents were asked to respond to the following questions (Table 2) as part of the trust component, where responses (a) included 13 local, state and federal organizations; both governmental and NGO's and (b) were given on a Likert Scale ( 1 = Strongly Disagree, 5 = Strongly Agree).

Table 2. Questions included in trust analysis.

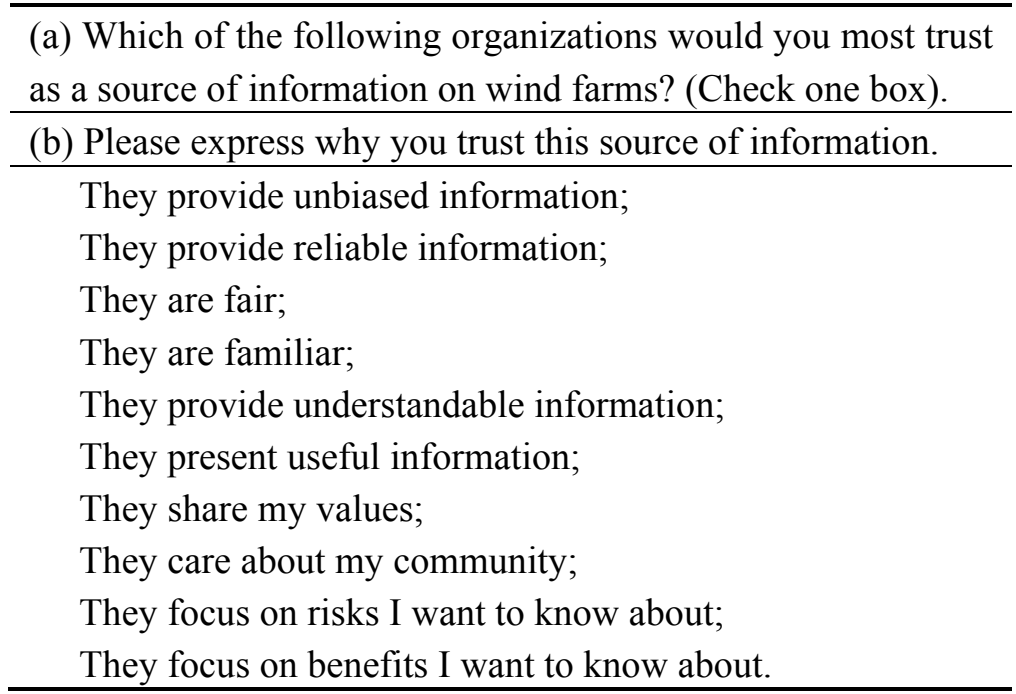

\section{Results}

The research reported here was designed to address three fundamental questions: (1) are environmental worldviews different across SSI researchers, where differences may serve as a boundary between disciplines?; (2) are SSI researchers and engaged stakeholders, and/or unengaged stakeholders (citizens) similar in environmental worldviews, where similarities may serve as common ground for sustainability science messaging?; and (3) what are the implications of incongruous and/or analogous worldviews on environmental communication effectiveness and approaches?

First, statistical analysis indicates important results for the unique population of researchers dedicated to sustainability science. In contrast to predicted outcome, no difference was observed between social $(\mathrm{M}=9.7, \mathrm{SD}=8.08)$ and natural scientists' $(\mathrm{M}=11.5, \mathrm{SD}=7.79)$ NEP scores $(\mathrm{z}=-0.69, p=0.49)$ in the faculty sample nor in the stakeholder sample controlled for gender (social, $\mathrm{M}=11.00, \mathrm{SD}=8.15$; natural, $\mathrm{M}=10.57, \mathrm{SD}=7.02 ; \mathrm{z}=0.49, p=0.62$ ). Of interest, however, women faculty members $(\mathrm{M}=13.26, \mathrm{SD}=7.88)$ reported statistically higher NEP scores than men faculty members $(\mathrm{M}=8.48, \mathrm{SD}=7.23)(\mathrm{z}=2.24, p=0.03)$. However, gender differences do not exist in the population sample (males, $\mathrm{M} 10.3, \mathrm{SD}=10.54$; females, $\mathrm{M}=12.3, \mathrm{SD}=8.52 ; \mathrm{z}=1.11, p=0.27$ ) nor in the stakeholder sample (males, $\mathrm{M}=9.60, \mathrm{SD}=7.39$; females, $\mathrm{M}=11.67, \mathrm{SD}=7.00 ; \mathrm{z}=1.33$, $p=0.18$ ) (Figure 2). In addition, we find that SSI university researchers $(\mathrm{M}=10.3, \mathrm{SD}=7.8)$, Maine's citizens $(\mathrm{M}=10.9, \mathrm{SD}=9.7)$, and sustainability conference stakeholders $(\mathrm{M}=10.4, \mathrm{SD}=7.6)$ do not have significantly different mean environmental worldviews as measured by the NEP $\left(\chi^{2}(2, N=316)=0.67, p=0.72\right)$. This finding is in direct contrast to Mainer's perceptions that university researchers do not share their values (see trust analysis below). In response to questions (1) and (2) posed above, empirical evidence suggests that all three groups-SSI faculty, engaged 
stakeholders and unengaged stakeholders hold similar means in environmental worldviews, as measured by the NEP.

Figure 2. Relationship of Gender and NEP score across samples; significant differences in NEP across Gender in faculty sample only.

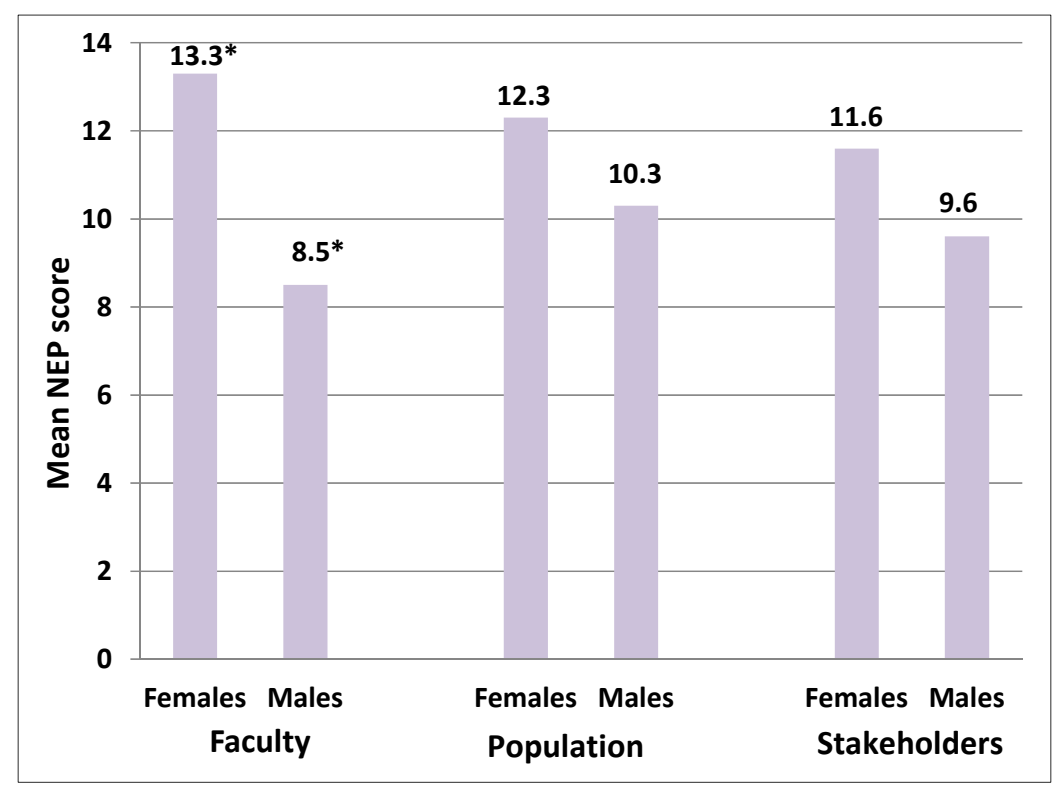

While the three groups exhibit similar means in environmental worldviews, distributional differences may be evident amongst the three groups, which may in turn impact knowledge-sharing behaviors and policy decision-making. We statistically tested these three groups for distributional differences and found evidence of statistical differences across engaged conference stakeholders, unengaged citizen stakeholders, and SSI researchers $\left(\chi^{2}(6, N=316)=12.63, p=0.04\right)$. SSI researcher and conference stakeholders do not have significantly different NEP score distributions $\left(\chi^{2}(3, N=160)=1.53, p=0.67\right)$. Testing revealed that SSI researchers do not have significantly different NEP score distributions from citizens $\left(\chi^{2}(3, N=214)=3.69, p=0.29\right)$. However, conference stakeholders and citizen stakeholders do have significantly different NEP score distributions $\left(\chi^{2}(3, N=258)=11.63, p=0.01\right)$, where alpha inflation associated with multiple pair-wise comparisons was corrected.

Despite the similarities evident in environmental worldviews, as reflected in the test results above, this common ground does not appear to motivate the trust that Maine citizens have in university researchers. In analysis of the trust component of the questionnaire, we find that of all thirteen entities provided to respondents, university researchers were the most trusted entity: $29 \%$ of respondents identified researchers as the most trusted source. When asked to express why university researchers were trusted, the most frequently reported response was, "They provide unbiased information." The least frequently reported response was, "They share my values," in direct contrast to our earlier findings of congruent NEP scores across the three populations (Figure 3). 
Figure 3. Trust of university researchers as information sources.

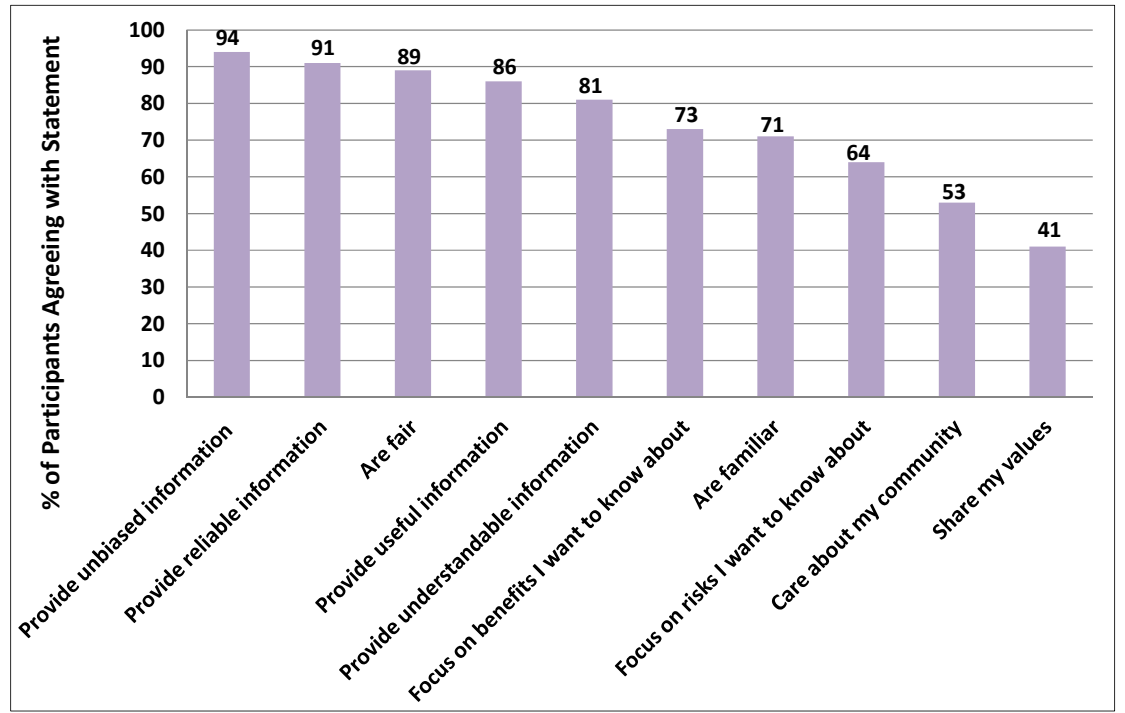

\section{Discussions and Conclusions}

\subsection{Limitations}

We acknowledge the limitations of this study. First, the stakeholders engaged in the survey were present at conferences specifically related to sustainability issues, and we recognize that this provides a biased sample as these individuals self-selected to engage with researchers and other parties interested in sustainability science. Secondly, the trust analysis must be used with caution. The phrase "share my values" may have been interpreted quite differently by respondents. Some may have felt that the values in question were endorsement of pro-ecological worldview (and thus appropriately measured by NEP). However, others may have interpreted this question to ask about financial or moral values unrelated to the questions at hand. Future studies should take care to discern or provide the precise meaning of the word "values" to respondents. Additionally, given the regimented order of the citizen survey sections, responses may exhibit order effects no investigated in this study.

\subsection{Implications}

Our results indicate that the interdisciplinary SSI faculty have similar environmental worldviews, here measured by the NEP, which may serve as common ground in tackling sustainability science issues. Although not the primary focus of this work, this finding has important implications for those who seek to engage in interdisciplinary collaboration focused on sustainability science. Our results suggest that interdisciplinary collaborations should recognize existing differences or similarities in worldviews, but also recognize that other differences may be significant as well $[53,54]$. The results have additional implications for initiatives that seek to engage with stakeholders, such as SSI. Our results suggest that identifying the worldviews of researchers may allow for a coherence of the research unit when communicating with communities and decision makers. As Lakoff [13] (p. 80) suggests, "successful social movements require coherence". 
Challenges emerge as we consider the impact of researcher-researcher relationships on researcher-stakeholder relationships. National Research Council and Clark et al. [55,56] indicate that information, particularly of a technical nature, enjoys greater use by citizens when users consider the information to be salient, credible, legitimate and actionable. Thus we must carefully consider whether any differing worldviews, concerns or priorities within the university community may hinder the ability of researchers to present a cohesive unit to Maine stakeholders and policy makers. Stakeholders may perceive a lack of unity among scientists regarding an issue as reason to devalue the information, as aptly stated by Jasanoff [57] "one's impressions of the reliability of scientific knowledge can differ depending on whether one looks at the public language of science or at the private language in which scientists communicate their assessments of certainty to each other" (p. 196). Recent work in climate denial [58] indicates that citizen perception of uncertainty among climate scientists undermines their confidence in the scientific outcome. Thus any boundaries that exist between academic disciplines may spillover into the already existing boundary between researchers and stakeholders as they struggle to prioritize the many issues surrounding sustainability science.

This research provides empirical evidence that university researchers engaged in sustainability science in Maine and the engaged stakeholders and unengaged stakeholders/citizens with whom they work all hold generally congruent environmental worldviews. However, we note distributional differences between engaged conference stakeholders and unengaged citizen stakeholders. These findings have direct implications for engagement efforts. If, as in the past, researchers have relied on engaged stakeholders (i.e., state government officials, NGOs, etc.) to carry sustainability science messages back to the general public, the differences in distribution of environmental worldviews between these two groups may inhibit productive communication. When we consider policy debates and public forums, typically organized by the entities who attend sustainability conferences, it is important to recognize that the debate may often be dictated by those in the tails of the general public distribution: an example of "the tail wagging the dog". Thus these often contentious sessions may not be reflective of the general level of environmental worldview agreement we find in our work.

\subsection{Future Research}

These results bring additional questions to the forefront. Given that worldviews impact or filter perception of an agent and their message: is communication of sustainability science more effective under shared or disparate values? If indeed parties involved in sustainability hold similar worldviews, is it beneficial or harmful to disclose this information during engagement? If researchers and citizens are more similar than citizens and conference stakeholders, how should researchers conceptualize how and with whom they communicate their findings?

At present, Maine citizens do not believe that university researchers share their values. The co-orientation model suggests that disclosure of our similarities will yield an opportunity for increased consensus, where citizens are currently operating under the illusion of false conflict regarding environmental values. However, the trust analysis reveals results more consistent with the Dunn and Woodstone model: Even if there is congruency in environmental worldviews, as bearers of scientific information, we must be cognizant of the complex boundaries that exist between stakeholders and universities. Future research aimed at determining which model correctly identifies 
these interactions would be very beneficial for environmental communication. Given that values are multi-dimensional the similarities noted in this research with respect to environmental worldviews leaves an open question on whether researchers, citizens and stakeholders may share, or conflict, on additional values. Understanding this complex relationship may allow for more effective message framing and can help to highlight the communicative relevance of worldviews in the sustainability science conversation.

\section{Acknowledgments}

The authors would like to gratefully acknowledge funding support by National Science Foundation award: EPS-0904155 to Maine EPSCoR at the University of Maine. We thank the members of Maine's Sustainability Solutions Initiative, the participants at the Maine Water Conference, Maine Wind Conference, and the people of Maine for taking the time to participate in this initiative. We thank two anonymous reviewers for constructive comments which improved this manuscript.

\section{Conflicts of Interest}

The authors declare no conflict of interest.

\section{References}

1. Van Kerkhoff, L.; Lebel, L. Linking knowledge and action for sustainable development. Annu. Rev. Env. Resour. 2006, 31, 445-477.

2. Norton, B.G. Searching for Sustainability: Interdisciplinary Essays in the Philosophy of Conservation Biology; Cambridge University Press: Cambridge, UK, 2003.

3. World Commission on Environment and Development. Our Common Future; Centre for Our Common Future: New York, NY, USA, 1992.

4. Kates, R.W. Readings in Sustainability Science and Technology; Center for International Development at Harvard University: Cambridge, MA, USA, 2010.

5. Arnstein, S.R. A ladder of citizen participation. J. Am. Inst. Plan. 1969, 35, 216-224.

6. Cash, D.; Borck, J.; Patt, A. Countering the loading-dock approach to linking science and decision making: Comparative analysis of el nino/southern oscillation (ENSO) forecasting systems. Sci. Technol. Human Values 2006, 31, 465-494.

7. Gibbons, M. Science's new social contract with society. Nature 1999, 402, C81-C84.

8. Habermas, J. Knowledge and Human Interests; Polity Press: Oxford, UK, 1968.

9. McNie, E.C. Reconciling the supply of scientific information with user demands: An analysis of the problem and review of the literature. Environ. Sci. Policy 2007, 10, 17-38.

10. Carlile, P.R. Transferring, translating, and transforming: An integrative framework for managing knowledge across boundaries. Organ. Sci. 2004, 15, 555-568.

11. Cash, D.; Clark, W.C.; Alcock, F.; Dickson, N.M.; Eckley, N.; Guston, D.H.; Jäger, J.; Mitchell, R.B. Knowledge systems for sustainable development. Proc. Natl. Acad. Sci. USA 2003, 100, 8086-8091.

12. Cox, R. Environmental Communication and the Public Sphere; SAGE Publications, Incorporated: Thousand Oaks, CA, USA, 2010. 
13. Lakoff, G. Why it matters how we frame the environment. Environ. Comm. J. Nat. Cult. 2010, 4, 70-81.

14. Hart, D.D.; Calhoun, A.J.K. Rethinking the role of ecological research in the sustainable management of freshwater ecosystems. Freshw. Biol. 2010, 55, 258-269.

15. Lindenfeld, L.A.; Hall, D.M.; McGreavy, B.; Silka, L.; Hart, D. Creating a place for environmental communication research in sustainability science. Environ. Comm. J. Nat. Cult. 2012, 6, 23-43.

16. Leong, K.M.; McComas, K.A.; Decker, D.J. Formative coorientation research: A tool to assist with environmental decision making. Environ. Comm. J. Nat. Cult. 2009, 2, 257-273.

17. Corbett, J.B. Communicating Nature: How We Create and Understand Environmental Messages; Island Press: Washington, DC, USA, 2006.

18. Cordano, M.; Welcomer, S.A.; Scherer, R.F. An analysis of the predictive validity of the new ecological paradigm scale. J. Environ. Educ. 2006, 34, 22-28.

19. Kassing, J.W.; Johnson, H.S.; Kloeber, D.N.; Wentzel, B.R. Development and validation of the Environmental Communication scale. Environ. Comm. J. Nat. Cult. 2010, 4, 1-21.

20. Dunlap, R.E.; van Liere, K.D.; Mertig, A.G.; Jones, R.E. Measuring endorsement of the New Ecological Paradigm: A revised NEP scale. J. Soc. Issues 2000, 56, 425-442.

21. Dunlap, R.E. The New Environmental Paradigm scale: From marginality to worldwide use. J. Environ. Educ. 2008, 40, 3-18.

22. Fielding, K.S.; McDonald, R.; Louis, W.R. Theory of planned behaviour, identity and intentions to engage in environmental activism. J. Environ. Psychol. 2008, 28, 318-326.

23. Teisl, M.F.; Anderson, M.W.; Noblet, C.L.; Criner, G.K.; Rubin, J.; Dalton, T. Are environmental professors unbalanced? Evidence from the field. J. Environ. Educ. 2011, 42, 67-83.

24. Erdogan, N. Testing the new ecological paradigm scale: Turkish case. Afr. J. Agr. Res. 2009, 4, 1023-1031.

25. Magee, R.G. Environmental Worldviews and Corporate Social Responsibility: A Theoretical Extension of the Persuasion Knowledge Model. Available online: http://www.allacademic.com/ meta/p300787_index.html (accessed on 19 September 2013).

26. Bostrom, A.; Barke, R.; Mohana, R.; Turaga, R.; O’Connor, R.E. Environmental concerns and the New Ecological Paradigm in Bulgaria. J. Environ. Educ. 2006, 37, 25-40.

27. Anderson, M.W.; Teisl, M.F.; Criner, G.; Tisher, S.; Smith, S.; Hunter, M.; Norton, S.A.; Jellison, J.; Alyokyin, A.; Gallandt, E.; et al. Attitudinal changes of undergraduate students in general education courses. J. Gen. Educ. 2011, 56, 149-168.

28. Hanna, A.A.; Sur, J.L.; Lee, H. Culture, the New Ecological Paradigm, and the Environment: The Direct and Mediated Effects of Culture on Environmentally Friendly Behaviors. Available online: http://www.allacademic.com/meta/p405008_index.html (accessed on 19 September 2013).

29. Albrecht, D.; Bultena, G.; Hoiberg, E.; Nowak, P. The New Environmental Paradigm scale. J. Environ. Educ. 1982, 13, 39-43.

30. Chang-Ho, J. Factor structure of the New Environmental Paradigm scale: Evidence from an urban sample in southern California. Psychol. Rep. 2004, 94, 125-130. 
31. Noblet, C.L.; Anderson, M.W.; Teisl, M.F. An empirical test of anchoring the NEP scale in environmental ethics. Environ. Educ. Res. 2013, 19, 540-551.

32. Norton, B.G. Toward Unity among Environmentalists; Oxford University Press: New York, NY, USA, 1991.

33. Muñoz-Erickson, T.A.; Cutts, B.B.; Larson, E.K.; Darby, K.J.; Neff, M.; Wutich, A.; Bolin, B. Spanning boundaries in an Arizona watershed partnership: Information networks as tools for entrenchment or ties for collaboration? Ecol. Soc. 2010, 15, 22-43.

34. Guston, D.H. Boundary organizations in environmental policy and science: An introduction. Sci. Technol. Human Values 2001, 26, 399-408.

35. Steel, B.S.; Warner, R.L.; Lach, D. Gender differences in support for scientific involvement in US environmental Policy. Sci. Technol. Human Values 2010, 35, 147-173.

36. Shephard, K.; Mann, S.; Smith, N.; Deaker, L. Benchmarking the environmental values and attitudes of students in New Zealand's post-compulsory education. Environ. Educ. Res. 2009, 15, 571-587.

37. Vikan, A.; Camino, C.; Biaggio, A.; Nordvik, H. Endorsement of the new ecological paradigm-A comparison of two Brazilian samples and one Norwegian sample. Environ. Behav. 2007, 39, 217-228.

38. McCoy, S.K.; Gardner, S.K. Interdisciplinary collaboration on campus: Five questions. Change 2012, 44, 44-49.

39. Bamberg, S.; Moser, G. Twenty years after Hines, Hungerford, and Tomera: A new meta-analysis of psycho-social determinants of pro-environmental behavior. J. Environ. Psychol. 2007, 27, 14-25.

40. Zelezny, L.; Chua, P.; Aldrich, C. Elaborating on gender differences in environmentalism. J. Soc. Issues 2000, 56, 443-457.

41. Giner-Sorolla, R.; Chaiken, S.; Lutz, S. Validity beliefs and ideology can influence legal case judgments differently. Law Hum. Behav. 2002, 26, 507-526.

42. Aaker, J.L. Accessibility or diagnosticity? Disentangling the influence of culture on persuasion processes and attitudes. J. Consum. Res. 2000, 26, 340-357.

43. Moser, S.C. Communicating climate change: History, challenges, process and future directions. Wiley Interdiscip. Rev. Clim. Change 2010, 1, 31-53.

44. Brønn, P.S.; Brønn, C. A reflective stakeholder approach: Co-orientation as a basis for communication and learning. J. Commun. Manag. 2003, 7, 291-303.

45. Grunig, J.; Hunt, T. Managing Public Relations; Holt, Rinehart and Winston: New York, NY, USA, 1984.

46. Freeman, R.E. Strategic Management: A Stakeholder Approach; Cambridge University Press: Cambridge, UK, 2010.

47. Friestad, M.; Wright, P. The Persuasion Knowledge model: How people cope with persuasion attempts. J. Consum. Res. 1994, 21, 1-31.

48. Constanzo, M.; Archer, D.; Aronson, E.; Pettigrew, T. Energy conservation behavior: The difficult path from information to action. Am. Psychol. 1986, 41, 521-528.

49. Woodward, G.C.; Denton, R.E. Persuasion \& Influence in American Life; Waveland Press, Incorporated: Long Grove, IL, USA, 1996. 
50. Dillman, D.; Smyth, J.; Christian, J. Mail and Internet Surveys: The Tailored Design Method-2007 Update with New Internet, Visual, and Mixed-Mode Guide; Wiley: Hoboken, NJ, USA, 2011.

51. Nunnally, J.C.; Bernstein, I.H. Psychometric Theory 3E; Tata McGraw-Hill Education: Noida, India, 2010.

52. Cortina, M. What is coefficient alpha? An examination of theory and application. J. Appl. Psychol. 1993, 78, 98-104.

53. Thompson, J.L. Building collective communication competence in interdisciplinary research teams. J. Appl. Commun. Res. 2009, 37, 278-297.

54. Lattuca, L.R. Learning interdisciplinarity: Sociocultural perspectives on academic work. J. High. Educ. 2002, 73, 711-739.

55. National Research Council of the National Academies. Our Common Future: A Transition Toward Sustainability; National Academies Press: Washington, DC, USA, 1999.

56. Clark, W.C.; Tomich, T.P.; van Noordwijk, M.; Guston, D.; Catacutan, D.; Dickson, N.M.; McNier, E. Boundary work for sustainable development: Natural resource management at the Consultative Group on International Agricultural Research. Proc. Natl. Acad. Sci. USA 2011, doi:10.1073/pnas.0900231108.

57. Jasanoff, S. Contested boundaries in policy-relevant science. Soc. Stud. Sci. 1987, 17, 195-230.

58. Norgaard, K.M. Living in Denial: Climate Change, Emotions, and Everyday Life; The MIT Press: Cambridge, MA, USA, 2011.

(C) 2013 by the authors; licensee MDPI, Basel, Switzerland. This article is an open access article distributed under the terms and conditions of the Creative Commons Attribution license (http://creativecommons.org/licenses/by/3.0/). 